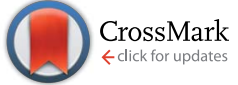

Cite this: RSC Adv., 2014, 4, 40859

\section{Photocatalysis in dimethyl carbonate green solvent: degradation and partial oxidation of phenanthrene on supported $\mathrm{TiO}_{2} \dagger$}

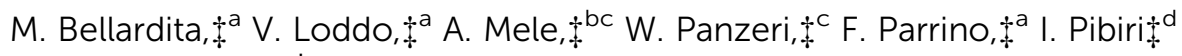 \\ and L. Palmisanot*a
}

Dimethyl carbonate (DMC) is here proposed - for the first time - as a green organic solvent for photocatalytic synthesis. In this work, the photocatalytic partial oxidation of phenanthrene in dimethyl carbonate (DMC) by using anatase $\mathrm{TiO}_{2}$ as the photocatalyst is described as paradigmatic example of a green synthetic process starting from polycyclic aromatic hydrocarbons (PAHs). For comparison, the same reaction carried out also in ethanol, 1-propanol or 2-propanol is reported. The use of DMC as the solvent allowed us to achieve $19 \%$ and $23 \%$ selectivity towards 9 -fluorenone and $6 \mathrm{H}$-benzo[c]chromen6 -one, respectively. The proposed approach may represent both a new green synthetic process and an environmentally friendly route to degradation of PAHs.
Received 25th June 2014

Accepted 18th August 2014

DOI: $10.1039 / c 4 r a 06222 a$

www.rsc.org/advances
Although photocatalytic reactions are usually carried out in water, which is the green solvent par excellence, ${ }^{15-19}$ the low solubility of PAHs in water does not allow to use it. PAHs oxidation is reported in solvents such as acetonitrile, ${ }^{5,6}$ wateracetone mixtures, ${ }^{7,8,13}$ subcritical water, ${ }^{9}$ and anionic and nonionic surfactant solutions. ${ }^{\mathbf{1 0}}$ Moreover, in some cases different amounts of $\mathrm{TiO}_{2}$ were mixed with contaminated soil samples to simulate the remediation of the soil surface. ${ }^{11,12}$ In recent years the use of photocatalysis as synthetic route has been proven to be a viable and sustainable alternative to classical chemical methods as it offers, under suitable experimental conditions, the possibility to stop the photoreaction before the total mineralization of the substrate, obtaining oxygenated products of industrial interest. ${ }^{20-24}$

Addressing the selectivity of photocatalytic reactions towards specific products is a challenging issue. In fact, photocatalysis involves radical chain reactions which produce often various products, although the selective formation of aromatic aldehydes from the corresponding alcohols has been reported. ${ }^{25}$ In the last case tuning the surface properties of the catalyst allowed desorption of the obtained oxygenated products, avoiding their further oxidation and mineralization. A moderate crystallinity of nanostructured $\mathrm{TiO}_{2}$ photocatalysts was found to be a key factor to increase the selectivity of the photocatalysts which, however, presented a low oxidant power.

In this paper the use of dimethyl carbonate (DMC) is proposed, for the first time, as a green organic solvent in heterogeneous photocatalysis using home prepared anatase $\mathrm{TiO}_{2}$ as the photocatalyst. Phenanthrene photocatalytic oxidation was carried out in a fixed bed total recirculating batch reactor containing Pyrex beads on which a home prepared $\mathrm{TiO}_{2}$ was supported. The partial photo-oxidation of phenanthrene is 
a paradigmatic example of photocatalytic synthesis using PAHs as substrates. DMC is a non-toxic and biodegradable compound and it can be synthesized without harmful reagents; its degradation does not give rise to toxic compounds, and its reactivity is tunable. DMC has been recently proposed as a green solvent, ${ }^{26}$ but its use under photocatalytic conditions is unprecedented. We demonstrate that the use of DMC instead of water dramatically enhances the selectivity of anatase $\mathrm{TiO}_{2}$ for the partial oxidation of phenanthrene, leading mainly to 9-fluorenone and $6 \mathrm{H}$-benzo[c]chromen-6-one. Conversely, the same reaction was carried out also in short chain alcohols (ethanol, 1and 2-propanol) but it led to complex reaction mixtures.

Fluorene family compounds are widely applied in many fields. They are used in applications of thermo and light sensitizer, liquid crystal chemistry, luminescence chemistry, polymers, spectrophotometric analysis, molecular chemistry and organometallic-complexes. Fluorenones are used in the formation of polyradicals for resins, in manufacturing antimalaria drugs and other pharmaceuticals and as ligands in the synthesis of metallocene catalysts. 9-Fluorenone, in particular, has been investigated as an attractive element of organic solar cells, and display devices. ${ }^{27}$ Some derivatives of fluorenone have been also detected in different orchidaceae plants. ${ }^{28}$ Most of the fluorenones are prepared by Friedel-Crafts acylation, ${ }^{29}$ remote metalation, ${ }^{30}$ and oxidation of fluorenes ${ }^{31}$ or fluorenols..$^{32}$ Other strategies for the synthesis of fluorenones include radical cyclization, ${ }^{33}$ coupling reactions of arylpalladium, ${ }^{34}$ and intramolecular dehydro Diels-Alder reactions. ${ }^{35}$ Chromenone derivatives are high value-added heterocyclic molecules which are very common in natural products as well as components of pharmacologically active compounds. ${ }^{36}$ Various synthetic methodologies have been devised for their synthesis. ${ }^{\mathbf{8} 37}$

\section{Experimental section}

The photocatalytic oxidation of phenanthrene (Fluka $>97 \%$ ) was carried out in an annular Pyrex home-made fixed bed continuous photoreactor (Fig. 1a) using DMC (Sigma-Aldrich 99\%), ethanol (Fluka $\geq 99.8 \%$ ), 1-propanol (Sigma-Aldrich $\geq 99.5 \%$ ) or 2-propanol (Fluka $\geq 99.9 \%$ ) as the solvents with or without small $(3 \% \mathrm{v} / \mathrm{v})$ amounts of water and $\mathrm{TiO}_{2}$ anatase as the photocatalyst. It can be noticed that as far as DMC is concerned higher amounts of water could not be used as a separation of the aqueous phase occurred. The same quantity of water was used also for the other solvents in order to compare the results. The use of a recirculating system with the immobilized catalyst avoided the need to separate the catalyst from the reaction mixture, and allowed to treat high reaction volumes of effluents with high concentration of substrate (magnitude order $\mathrm{g} \mathrm{L}^{-1}$ ).

A $1000 \mathrm{~W}$ medium pressure $\mathrm{Hg}$ lamp (Helios Italquartz, Italy) was axially positioned inside the reactor which was cooled by water circulating through a Pyrex thimble. The inner part of the annulus contained a fixed bed of Pyrex beads (diameter $2 \mathrm{~mm}$; bed height $150 \mathrm{~mm}$ ) covered by a thin layer of home prepared $\mathrm{TiO}_{2}$.

The photocatalytic bed was prepared according to a procedure reported in literature. ${ }^{38}$ Titanium tetrachloride (Fluka

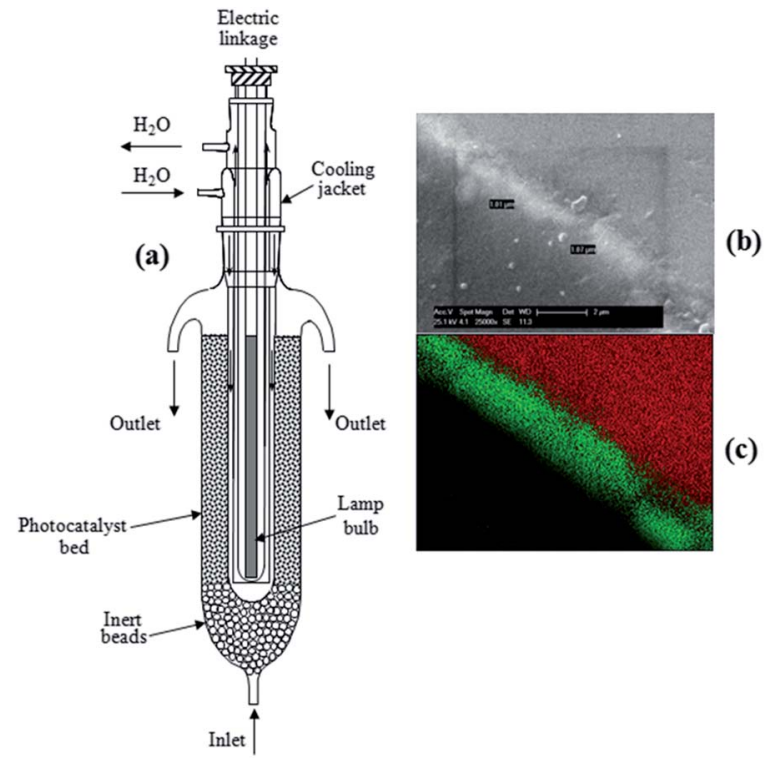

Fig. 1 Fixed-bed photoreactor (a), cross-section micrograph (b) and EDAX mapping (c) of a layer of $\mathrm{TiO}_{2}$ supported on a glass bead.

98\%) was used as precursor for the catalyst without any further purification. $\mathrm{TiCl}_{4}$ was slowly added to distilled water (volume ratios $1: 10$ ) at room temperature. The hydrolysis reaction was highly exothermic, produced high quantities of $\mathrm{HCl}$ fumes and a clear solution was obtained after $10 \mathrm{~h}$ stirring. The Pyrex beads were added to the solution and were kept in there for 30 minutes. After that they were filtered in order to eliminate the supernatant liquid and placed in a Pyrex tube (maintained at a temperature of $423 \mathrm{~K}$ ) having a porous frit at the bottom through which a flow of nitrogen was fed for $1.5 \mathrm{~h}$ until the $\mathrm{TiCl}_{4}$ was completely hydrolysed to $\mathrm{Ti}(\mathrm{OH})_{4}$. A thermal treatment at $673 \mathrm{~K}$ for three hours in air was then performed and the procedure was repeated in order to support two layers on the beads. A thin layer of $\mathrm{TiO}_{2}$ as anatase phase was obtained, as confirmed by XRD analysis carried out with a Philips diffractometer using $\mathrm{Cu} \mathrm{K} \alpha$ radiation and a $2 \theta$ scan rate of $1.2^{\circ} \mathrm{min}^{-1}$.

A cross-section micrograph (b) and an EDAX mapping (c) of a layer of $\mathrm{TiO}_{2}$ supported on a glass bead are shown in Fig. 1. The last pictures were obtained by using a Philips XL30 ESEM scanning electron microscope (SEM), operating at $30 \mathrm{kV}$ on specimens upon which a thin layer of gold was deposited. The experimental runs were carried out in the following way. A flask containing $500 \mathrm{~mL}$ of $10 \mathrm{mM}$ phenanthrene solution was used to feed the photoreactor through a peristaltic pump. The solution was saturated with $\mathrm{O}_{2}$ during the photocatalytic runs and samples were withdrawn at fixed intervals of time. Preliminary tests were carried out under the same experimental conditions to ensure that the covered beads did not release appreciable amounts of catalyst during the runs.

The quantitative determination of phenanthrene was performed by means of a HPLC Beckman Coulter (System Gold 126 Solvent Module and 168 Diode Array Detector), equipped with a Phenomenex Kinetex $5 \mu \mathrm{m} \mathrm{C18} \mathrm{100A} \mathrm{column}(4.6 \mathrm{~mm} \times 150$ $\mathrm{mm}$ ) working at room temperature. The eluent consisted of a 
mixture of acetonitrile (VWR chemicals $\geq 99.9 \%$ ) and $1 \mathrm{mM}$ trifluoroacetic acid (Sigma-Aldrich $\geq 98 \%$ ) aqueous solution (20: 80 volumetric ratio) and the flow rate was $0.8 \mathrm{~mL} \mathrm{~min}{ }^{-1}$. GC-MS analysis were performed in order to identify some intermediates in the reaction mixture. To this aim, a Thermo Fisher ITQ900 instrument, equipped with a Thermo Scientific TGWAXMS A $30 \mathrm{~m} \times 0.25 \mathrm{~mm} \times 0.25 \mu \mathrm{m}$ column was used. A temperature ramp was applied as follows: $150{ }^{\circ} \mathrm{C}$ for 4 minutes, $1.5^{\circ} \mathrm{C} \min ^{-1}$ up to $250{ }^{\circ} \mathrm{C}$ and 40 minutes at $250^{\circ} \mathrm{C}$. Electrospray ionization mass spectrometry (ESI-MS) was carried out on a Bruker Esquire $3 \mathrm{~K}^{+}$instrument equipped with an ion trap detector (ITD). Solutions were introduced in the ESI source by an infusion pump operating with a flow rate of $5 \mathrm{~L} \mathrm{~min}^{-1}$. GCMS analysis of the isolated products were performed on a Shimadzu GC-MS QP2010 Plus. ${ }^{1} \mathrm{H}$ NMR spectra (250 and $400 \mathrm{MHz}$ ) and ${ }^{13} \mathrm{C}$ NMR spectra (62.5 and $100 \mathrm{MHz}$ ) were taken on Bruker spectrometers. Flash chromatography was performed using silica gel (200-400 mesh) and mixtures of ethyl acetate (VWR chemicals) and light petroleum (VWR chemicals, fraction boiling in the range $40-60{ }^{\circ} \mathrm{C}$ ) in various ratios, and allowed to<smiles>c1ccc2ccccc2c1</smiles>

phenanthrene

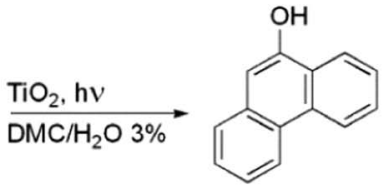

9-hydroxyphenanthrene

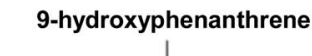

9,10-phenanthrenedion (identified by GC-MS)

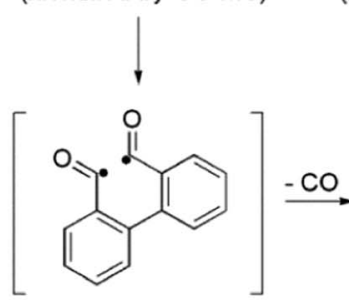
10-dihydroxyphenanthre
(identified by GC-MS)<smiles>Oc1c(O)c2ccccc2c2ccccc12</smiles>
10-dihydroxyphenanthrene
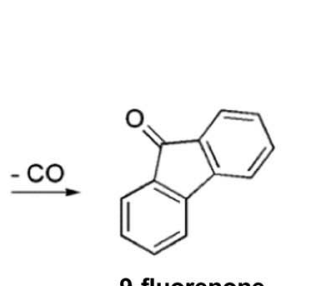

9-fluorenone $19 \%$ isolated by CC \begin{tabular}{l|l}
$\mathrm{DMC} / \mathrm{H}_{2} \mathrm{O}_{2}$ \\
$\mathrm{TiO}_{2}$
\end{tabular} \mid $\begin{gathered}\text { Baeyer-Villiger } \\
\text { oxidation }\end{gathered}$

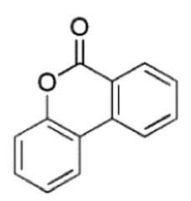

6H-benzo[c]chromen-6-one $23 \%$ isolated by CC

Scheme 1 Proposed reaction pathways to 9-fluorenone and $6 \mathrm{H}$ benzo[c]chromen-6-one. obtain 9-fluorenone $(0.123 \mathrm{~g}, 19 \%$ yield calculated with respect to the converted phenanthrene) and $6 H$-benzo $[c]$ chromen-6-one $(0.158 \mathrm{~g}, 23 \%$ yield calculated with respect to the converted phenanthrene), in addition to phenanthrene recovered $(0.277 \mathrm{~g})$ and trace amounts of unidentified by-products. Spectral data are reported within the paper and in the SI section. Some experiments were performed in order to clarify the last step of the proposed reaction mechanism (see Scheme 1 below) in the following way: $0.05 \mathrm{~g}$ of 9-fluorenone (Fluka >99\%) were dissolved in $50 \mathrm{~mL}$ DMC and $28.6 \mathrm{~mL}$ of $\mathrm{H}_{2} \mathrm{O}_{2}$ (Sigma-Aldrich $30 \%$ $\mathrm{w} / \mathrm{w})$. This mixture was poured into a $100 \mathrm{~mL}$ round bottom flask and refluxed $12 \mathrm{~h}$ by bubbling $\mathrm{O}_{2}$ at $50{ }^{\circ} \mathrm{C}$ in the dark. Similar tests were carried out under the same experimental conditions but (i) in the presence of $15 \mathrm{mg}$ of the $\mathrm{TiO}_{2}$-covered Pyrex beads and (ii) by substituting DMC with the same amount of ethanol. In all cases the solvent was removed by freeze-drying after the reaction and the residue was dissolved with ethylacetate and analyzed by GC-MS.

\section{Results and discussions}

The time course for the photo-oxidation of phenanthrene in the presence of ethanol and ethanol- $\mathrm{H}_{2} \mathrm{O}(3 \% \mathrm{v} / \mathrm{v})$ mixture as the solvents is illustrated in Fig. 2. The reaction rate was higher in the presence of water, giving rise to an almost complete degradation of phenanthrene after about $50 \mathrm{~h}$ of irradiation. Possibly, in this case the presence of water enhanced $\mathrm{OH}$ radicals production and/or the recovery of surface active sites of the photocatalyst which in turn contributed to phenanthrene oxidation. In fact, the water molecules in the reacting mixture may be oxidized by the photogenerated holes $\left(\mathrm{h}^{+}\right)$according to the following equation: ${ }^{39}$

$$
\mathrm{H}_{2} \mathrm{O}+\mathrm{h}^{+} \rightarrow \cdot \mathrm{OH}+\mathrm{H}^{+}
$$

In the presence of 1- or 2-propanol the phenanthrene oxidation rate was lower than in the case of ethanol as only $60 \%$ conversion was achieved after $90 \mathrm{~h}$ irradiation. Nevertheless the co-presence of

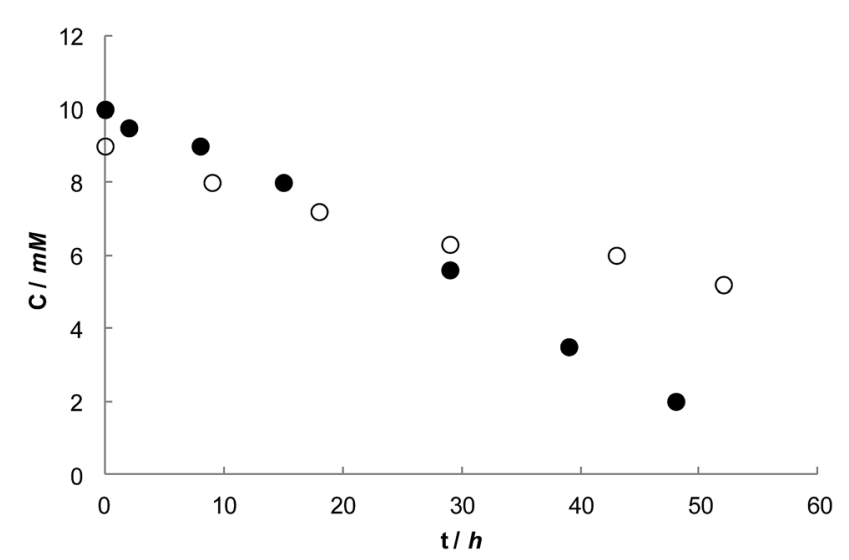

Fig. 2 Phenanthrene concentration versus reaction time for representative runs carried out in the presence of ethanol (empty circles) and ethanol $-\mathrm{H}_{2} \mathrm{O}(3 \% \mathrm{v} / \mathrm{v})$ mixture (full circles) as the solvents. 
water did not influence the photoreaction rate in 1- or 2-propanol. The different behaviour of ethanol with respect to 1- and 2-propanol can be tentatively attributed to the chain length of propanol molecules which could compete more strongly with water for the adsorption on the surface sites and/or to a different $\mathrm{OH}$ radicals scavenger ability of 1- and 2-propanol with respect to ethanol. The oxidation by-products were detected and identified by means of both electrospray ionization mass spectrometry (ESI-MS) and GC-MS analysis. When ethanol was used as the solvent, several products were found after $\mathrm{ca}$. 80\% conversion of phenanthrene: 2-methyl-9H-fluorene; 9-methylene-fluorene; ethoxy2,2'-diphenic acid diethyl ester; ethyl-2,2'-diphenic acid diethyl ester; phthalic acid ethyl ester; 2-phenylbenzoic acid ethyl ester; 2,2'-diphenic acid diethyl ester; $2,2^{\prime}$-diphenic acid ethyl ester; 9H-fluorene; 3-hydroxyphenanthrene; 9,10-dihydroxyphenanthrene; 9,10-phenanthrenedione; 2,2'-diphenic acid; 9-fluorenone and $6 H$-benzo $[c]$ chromen-6-one. Most of the products found when 1- or 2-propanol were used as the solvents are the same of those observed in the presence of ethanol except those resulting from the insertion of the ethyl or ethanoate groups in the phenanthrene molecule which are replaced by compounds in which the propyl or the propylate groups are present. The presence of some of these compounds in comparable amounts, as evidenced by parallel GCMS, HPLC and TLC analysis, indicates that the photo-reaction is not selective and the alcohols used as the solvents work also as reagents.

Fig. 3 shows the degradation of phenanthrene in DMC with and without water as the co-solvent.

Phenanthrene conversion occurred only in the presence of water, as the reaction rate was negligible in pure DMC. The photo-oxidation rate was slower than when ethanol was used as the solvent. Nevertheless, although phenanthrene reacted faster in the alcohols than in DMC, in the latter case the reaction gave two main products only, thus showing a greatly enhanced selectivity compared to the alcohols. For instance, a run lasting $250 \mathrm{~h}$ ( $\mathrm{ca}$. 60\% conversion of phenanthrene) produced 9-fluorenone and $6 H$-benzo $[c]$ chromen-6-one with $19 \%$ and $23 \% \mathrm{w} / \mathrm{w}$ yield, respectively, calculated with respect to the converted

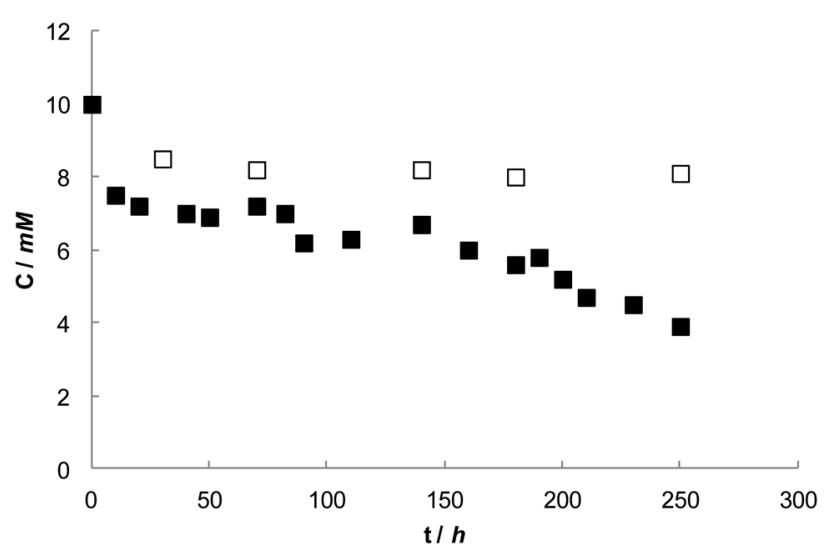

Fig. 3 Phenanthrene concentration versus reaction time for representative runs carried out in the presence of DMC (empty squares) and DMC $-\mathrm{H}_{2} \mathrm{O}(3 \% \mathrm{v} / \mathrm{v})$ mixture (full squares) as the solvents. phenanthrene. Among the many other products that were identified by GC-analysis, we report 9-hydroxyphenanthrene; 9,10-dihydroxyphenanthrene; 9,10-phenanthrenedione; 2,2'diphenic acid; 1,2-benzenedicarboxylic acid monobutylester; 1,2-benzenedicarboxylic acid bis(2-methylpropyl)ester; 1,2-benzenedicarboxylic acid diisooctyl ester; didodecylphthalate; bis(2-ethylhexyl)phthalate; 2-(1-oxopropyl)benzoic acid; farnesol; phenanthrene-9-carboxaldehyde, but they were found only in very small concentrations or in traces and a detailed analytical quantitative investigation of all of these very minor products is out of the scope of this work. DMC did not appreciably react with phenanthrene as no methylated products were detected by GC-MS analysis. Notably some reactivity of DMC has been reported for the catalytic transesterification of alcohols into methyl carbonates in the presence of $\mathrm{TiO}_{2}$ nanofibers, ${ }^{40}$ differently from the photocatalytic process here reported.

In our system $6 H$-benzo[c]chromen-6-one was first identified by electrospray ionization mass spectrometry (ESI-MS) by direct infusion of the reaction mixture in the mass spectrometer source as an intense peak at $\mathrm{m} / \mathrm{z} 197$, corresponding to $\left[\mathrm{C}_{13} \mathrm{H}_{9} \mathrm{O}_{2}\right]^{+}$. Isolation and collision induced decomposition (CID) of $\mathrm{m} / \mathrm{z} 197$ gave the ion at $\mathrm{m} / \mathrm{z} 153$ as the major fragment ions, consistent with neutral loss of 44 Da (see ESI, Fig. S1†). Identical CID pattern was found on a standard sample of $6 \mathrm{H}^{-}$ benzo $[c]$ chromen-6-one synthesized on purpose, thus providing a fingerprint confirmation of the molecular structure. For the full characterization, the two main products (9-fluorenone and $6 H$-benzo $[c]$ chromen-6-one) were isolated by preparative column chromatography with silica flash and mixtures of petroleum and ethyl acetate in various ratios, identified by GCMS (Fig. 4) and extensive NMR analyses (see ESI, Fig. S2-S8†) and compared with standards. Herein the spectroscopic data of the two main isolated products are reported.

9-Fluorenone, yellow solid, ${ }^{1} \mathrm{H}$ NMR (250 MHz, $\left.\mathrm{CDCl}_{3}\right): \delta 7.67$ $(\mathrm{d}, J=7.3 \mathrm{~Hz}, 2 \mathrm{H}), 7.45-7.55(\mathrm{~m}, 4 \mathrm{H}), 7.26-7.33(\mathrm{~m}, 2 \mathrm{H}) .{ }^{13} \mathrm{C} \mathrm{NMR}$ $\left(62.5 \mathrm{MHz}, \mathrm{CDCl}_{3}\right): \delta 193.8,144.4,134.6,134.2,129.1,124.3$, 120.3. GC-MS ( $m / z$, relative intensity): $180\left(\mathrm{M}^{+}, 100\right), 152(50), 126$

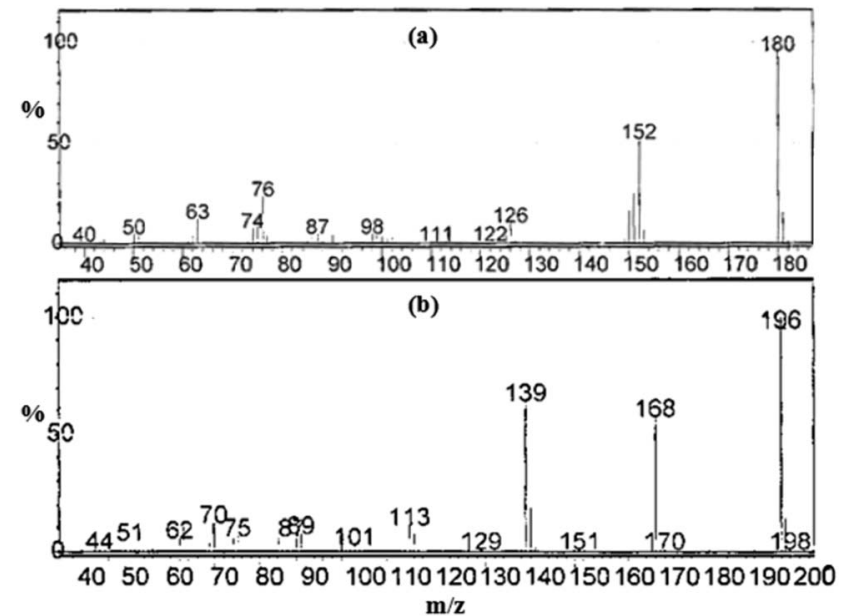

Fig. 4 GC-MS analyses of the isolated 9-fluorenone (a) and 6H-benzo [c]chromen-6-one (b) 
(10), 76 (24), 63 (13). 6H-Benzo[c]chromen-6-one, white solid, ${ }^{1} \mathrm{H}$ NMR (400 MHz, $\mathrm{CDCl}_{3}$ ): $\delta 8.43(\mathrm{dd}, J=8.0$ and $1.3 \mathrm{~Hz}, 1 \mathrm{H}), 8.15$ (br d, $J=8.1 \mathrm{~Hz}, 1 \mathrm{H}$ ), 8.09 (dd, $J=7.9$ and $1.5 \mathrm{~Hz}, 1 \mathrm{H}$ ), 7.86 (ddd, $J=7.5,7.5$ and $1.5 \mathrm{~Hz}, 1 \mathrm{H}$ ), 7.62 (ddd, $J=7.6,7.6$ and $1.4 \mathrm{~Hz}, 1 \mathrm{H}$ ), 7.52 (ddd, $J=7.7,7.7$ and $1.5 \mathrm{~Hz}, 1 \mathrm{H}$ ), 7.40 (dd, $J=7.9$ and 1.2 $\mathrm{Hz}, 1 \mathrm{H}$ ), 7.37 (ddd, $J=7.1,7.1$ and $1.4 \mathrm{~Hz}, 1 \mathrm{H}) .{ }^{13} \mathrm{C}$ NMR $(100$ $\mathrm{MHz}, \mathrm{CDCl}_{3}$ ): $\delta 161.2,151.3,134.8,134.8$ (q), 130.6, 130.4, 128.9, $124.5,122.8,121.7,121.3,118.1,117.8$. GC-MS $(\mathrm{m} / \mathrm{z}$, relative intensity): 196 ( $\left.\mathrm{M}^{+}, 100\right), 168$ (60), 139 (65), 113 (13), 70 (13).

The reaction mechanism hypothesized involves the initial hydroxylation of phenanthrene by radicals produced through $\mathrm{TiO}_{2}$ photocatalysis. In fact, the charge carriers photogenerated upon $\mathrm{TiO}_{2}$ excitation can give rise both to direct oxidation of the substrate and to indirect oxidation by highly oxidizing species produced through water oxidation or oxygen reduction. It is worth noting that the first attack to phenanthrene occurs at position 9 and 10 according to the Dewar molecular-orbital theory. ${ }^{41}$ The hydroxylated intermediates in turn undergo different pathways, strongly depending on the different solvent present. In order to justify the formation of the two main products isolated when the photocatalytic reaction was performed in DMC- $\mathrm{H}_{2} \mathrm{O}(3 \% \mathrm{v} / \mathrm{v})$, the reaction mechanism shown in Scheme 1 was hypothesized. The suggested path involves the initial double hydroxylation at position 9 and 10 of phenanthrene, affording 9,10-dihydroxyphenanthrene which was detected by means of GC-MS analysis when both DMC- $\mathrm{H}_{2} \mathrm{O}(3 \% \mathrm{v} / \mathrm{v})$ and ethanol- $\mathrm{H}_{2} \mathrm{O}$ $(3 \% \mathrm{v} / \mathrm{v})$ were used as the solvents. This intermediate undergoes oxidation giving the corresponding diketone which was detected in the aforementioned analysis as well. The diketone gives rise, through homolytic rupture of the C9-C10 bond, to a not isolable double radical intermediate, which in turn, after decarbonylation and ring closure, affords 9-fluorenone.

This latter compound is converted by a Baeyer-Villiger reaction to $6 H$-benzo[ $c]$ chromen-6-one, involving hydroperoxide species which are likely present in the reaction medium (possibly deriving from water which interacts under irradiation in the presence of $\mathrm{O}_{2}$ on the $\mathrm{TiO}_{2}$ surface). The last step of the proposed mechanism consists in a dark reaction between peroxo-species and 9-fluorenone. Some qualitative tests were performed in order to understand the influence of $\mathrm{TiO}_{2}$ in the Baeyer-Villiger step (details are reported in the Experimental section). A mixture of DMC, $\mathrm{H}_{2} \mathrm{O}_{2}$ and 9-fluorenone was stirred by bubbling $\mathrm{O}_{2}$ overnight at $50{ }^{\circ} \mathrm{C}$ in the presence or in the absence of the $\mathrm{TiO}_{2}$-covered Pyrex beads. Surprisingly $6 \mathrm{H}$-benzo $[c]$ chromen-6-one was detected by GC-MS analyses, both in the presence and in the absence of $\mathrm{TiO}_{2}$. This finding indicates that the Baeyer-Villiger oxidation occurs in the presence of DMC and $\mathrm{H}_{2} \mathrm{O}_{2}$ also without catalyst. ${ }^{42}$

On the other hand, $6 H$-benzo $[c]$ chromen-6-one was found only in the presence of $\mathrm{TiO}_{2}$ when ethanol was used as the solvent, whereas it was absent without catalyst. This last result indicates that Baeyer-Villiger oxidation could be catalyzed with low yields in the presence of $\mathrm{TiO}_{2}$, analogously to what reported in the literature. ${ }^{43}$

Therefore the production of $6 \mathrm{H}$-benzo[c]chromen-6-one in our reacting system can occur by the Baeyer-Villiger reaction through two pathways: the first one through organic peroxo- species, likely formed by reaction between DMC and photogenerated $\mathrm{H}_{2} \mathrm{O}_{2}$, the second one in the presence of $\mathrm{TiO}_{2}$ as the catalyst and $\mathrm{H}_{2} \mathrm{O}_{2}$.

DMC can play an active role as precursor for the in situ formation of organic peroxo-species which in turn induce chromenone formation. Formation of monoperoxy carbonic acid monomethyl ester from DMC oxidation through $\mathrm{H}_{2} \mathrm{O}_{2}$ was reported in literature ${ }^{\mathbf{4}}$ only in the presence of an enzymatic catalyst.

The presence of other by-products in trace amounts evidenced by GC-MS analysis, can be explained by taking into account further reaction of some of the intermediates illustrated in the Scheme 1. For instance 2,2-diphenic acid could be produced by $\mathrm{OH}$ radicals attack to the diradical, whereas 3hydroxyphenanthrene could be likely produced by a different regiodirected hydroxylation in position $\mathrm{C} 3$ of phenanthrene. The ethyl esters produced when ethanol- $\mathrm{H}_{2} \mathrm{O}(3 \% \mathrm{v} / \mathrm{v})$ was used as the solvent, are likely due to the attack of EtO radicals to the various intermediates. Finally, it cannot be excluded a parallel pathway affording $\mathrm{CO}_{2}$ and water after various oxidant attacks to adsorbed intermediates species. In summary, the unprecedented use of DMC as reaction medium for $\mathrm{TiO}_{2}$ photocatalyzed partial oxidation of phenanthrene showed the possibility to achieve both good conversion yield and selectivity.

\section{Conclusions}

The photocatalytic partial oxidation of phenanthrene in dimethyl carbonate was carried out in a fixed bed total recirculating batch reactor containing Pyrex beads covered with $\mathrm{TiO}_{2}$ anatase. This system avoids the separation of the catalyst from the reaction mixture, and allows to treat high reaction volumes of effluents with high concentration of substrate. For comparison, the same reaction was also performed in ethanol, 1-propanol or 2-propanol. The use of dimethyl carbonate as the solvent allowed to achieve $19 \%$ and $23 \%$ of selectivity towards 9-fluorenone and $6 \mathrm{H}$-benzo[ $\mathrm{c}]$ chromen-6-one, respectively. On the contrary aliphatic alcohols took part in the reaction producing a large variety of products. These findings open the route to a sustainable process targeted to both the degradation of polycyclic aromatic hydrocarbons as disposal strategy and to the synthesis of potentially interesting products.

\section{Acknowledgements}

NMR experimental data were provided by Centro Grandi Apparecchiature - UniNetLab - Università di Palermo funded by P.O.R. Sicilia 2000-2006, Misura 3.15 Quota Regionale. M.B., V.L., F.P. and L.P. wish to thank MIUR (Rome) for financial support (Project: PON02_00153_2849085).

\section{Notes and references}

1 O. T. Woo, W. K. Chung, K. H. Wong, A. T. Chow and P. K. Wong, J. Hazard. Mater., 2009, 168, 1192. 
2 V. Augugliaro, M. Bellardita, V. Loddo, G. Palmisano, L. Palmisano and S. Yurdakal, J. Photochem. Photobiol., C, 2012, 13, 224; G. Palmisano, E. García-López, G. Marcì, V. Loddo, S. Yurdakal, V. Augugliaro and L. Palmisano, Chem. Commun., 2010, 46, 7074; S. Yurdakal, G. Palmisano, V. Loddo, V. Augugliaro and L. Palmisano, J. Am. Chem. Soc., 2008, 130, 1568.

3 H. F. Lin and K. T. Valsaraj, J. Hazard. Mater, 2003, 99, 203.

4 S. Dass, M. Muneer and K. R. Gopidas, J. Photochem. Photobiol., A, 1994, 77, 83.

5 S. Kohtani, M. Tomohiro, K. Tokumura and R. Nakagaki, Appl. Catal., B, 2005, 58, 265; H. Jia, J. Zhao, X. Fan, K. Dilimulati and C. Wang, Appl. Catal., B, 2012, 123, 43.

6 S. Higashida, A. Harada, R. Kawakatsu, N. Fujiwara and M. Matsumura, Chem. Commun., 2006, 2804.

7 J. Kou, Z. Li, Y. Guo, J. Gao, M. Yang and Z. Zou, J. Mol. Catal. A: Chem., 2010, 325, 48.

8 J. Kou, Z. Li, Y. Yuan, H. Zhang, Y. Wang and Z. Zou, Environ. Sci. Technol., 2009, 43, 2919.

9 Y. Yang and F. Hildebrand, Anal. Chim. Acta, 2006, 555, 364. 10 Y. Zhang, J. W. C. Wong, P. Liu and M. Yuan, J. Hazard. Mater., 2011, 191, 136.

11 D. Dong, P. Li, X. Li, C. Xu, D. Gong, Y. Zhang, Q. Zhao and P. Li, Chem. Eng. J., 2010, 158, 378.

12 J. Gu, D. Dong, L. Kong, Y. Zheng and X. Li, J. Environ. Sci., 2012, 24, 2122.

13 A. K. Haritash and C. P. Kaushik, J. Hazard. Mater., 2009, 169, 1.

14 S. B. Hawthorne, Y. Yang and D. J. Miller, Anal. Chem., 1994, 66, 2912.

15 V. Kitsiou, N. Filippidis, D. Mantzavinos and I. Poulios, Appl. Catal., B, 2009, 86, 27.

16 A. Di Paola, M. Bellardita, G. Marcì, L. Palmisano, F. Parrino and R. Amadelli, Catal. Today, 2011, 161, 35.

17 A. Di Paola, M. Bellardita, R. Ceccato, L. Palmisano and F. Parrino, J. Phys. Chem. C, 2009, 113, 15166.

18 M. R. Hoffmann, S. T. Martin, W. Choi and D. W. Bahnemann, Chem. Rev., 1995, 95, 69.

19 G. Marcì, A. Di Paola, E. García-López and L. Palmisano, Catal. Today, 2007, 129, 16.

20 L. Palmisano, V. Augugliaro, M. Bellardita, A. Di Paola, E. García-López, V. Loddo, G. Marci, G. Palmisano and S. Yurdakal, ChemSusChem, 2011, 4, 1431.

21 V. Augugliaro, G. Camera-Roda, V. Loddo, G. Palmisano, L. Palmisano, F. Parrino and M. A. Puma, Appl. Catal., B, 2012, 111, 555.

22 F. Parrino, A. Ramakrishnan, C. Damm and H. Kisch, ChemPlusChem, 2012, 77, 713.

23 M. Bellardita, V. Loddo, G. Palmisano, I. Pibiri, L. Palmisano and V. Augugliaro, Appl. Catal., B, 2014, 144, 607.

24 A. Pace and S. Barreca, Curr. Org. Chem., 2013, 17, 3032.

25 V. Augugliaro, H. Kisch, V. Loddo, M. J. López-Muñoz, C. Márquez-Álvarez, G. Palmisano, L. Palmisano, F. Parrino and S. Yurdakal, Appl. Catal., A, 2008, 349, 182; V. Augugliaro, H. Kisch, V. Loddo, M. J. López-Muñoz, C. Márquez-Álvarez, G. Palmisano, L. Palmisano, F. Parrino and S. Yurdakal, Appl. Catal., A, 2008, 349, 189.

26 P. Tundo and M. Selva, Acc. Chem. Res., 2002, 35, 706.
27 S. Kawasaki, F. Jin and T. Takata, in Metal, Ceramic and Polymeric Composites for Various Uses, ed. J. Cuppoletti, 2011, ch. 18, ISBN 978-953-307-353-8; D. A. Shultz, J. C. Sloop and G. Washington, J. Org. Chem., 2006, 71, 9104; H. Usta, A. Facchetti and T. J. Marks, Org. Lett., 2008, 10, 1385.

28 S. K. Talapatra, S. Bose, A. K. Mallik and B. Talapatra, Tetrahedron, 1985, 41, 2765; C. Fan, W. Wang, Y. Wang, G. Qin and W. Zhao, Phytochemistry, 2001, 57, 1255.

29 J. Barluenga, M. Trincado, E. Rubio and J. M. González, Angew. Chem., Int. Ed., 2006, 45, 3140; R. K. Chinnagolla and M. Jeganmohan, Org. Lett., 2012, 14, 5246.

30 D. Tilly, S. S. Samanta, A. De, A. S. Castanet and J. Mortier, Org. Lett., 2005, 7, 827; M. Alessi, A. L. Larkin, K. A. Ogilvie, L. A. Green, S. Lai, S. Lopez and V. Snieckus, J. Org. Chem., 2007, 72, 1588.

31 G. Yang, Q. Zhang, H. Miao, X. Tong and J. Xu, Org. Lett., 2005, 7, 263; A. J. Catino, J. M. Nichols, H. Choi, S. Gottippamula and M. P. Doyle, Org. Lett., 2005, 7, 5167.

32 T. P. Liu, Y. X. Liao, C. H. Xing and Q. S. Hu, Org. Lett., 2011, 13, 2452; X. Bei, A. Hagemeyer, A. Volpe, R. Saxton, H. Turner and A. S. Guram, J. Org. Chem., 2004, 69, 8626.

33 Z. Shi and F. Glorius, Chem. Sci., 2013, 4, 829; S. Wertz, D. Leifert and A. Studer, Org. Lett., 2013, 15, 928.

34 J. P. Waldo, X. Zhang, F. Shi and R. C. Larock, J. Org. Chem., 2008, 73, 6679; S. Paul, S. Samanta and J. K. Ray, Tetrahedron Lett., 2010, 51, 5604.

35 D. Rodríguez, M. F. Martínez-Esperón, A. Navarro-Vázquez, L. Castedo, D. Domínguez and C. Saá, J. Org. Chem., 2004, 69, 3842.

36 X. Zhang, P. Qiao, X. Ji, J. Han, L. Liu, B. L. Weeks, Q. Yao and Z. Zhang, ACS Sustainable Chem. Eng., 2013, 1, 974; T. Hosoya, E. Takashiro, T. Matsumoto and K. Suzuki, J. Am. Chem. Soc., 1994, 116, 1004; K. Koch, J. Podlech, E. Pfeiffer and M. J. Metzler, J. Org. Chem., 2005, 70, 3275.

37 N. Thasana, R. Worayuthakarn, P. Kradanrat, E. Hohn, L. Young and S. Ruchirawat, J. Org. Chem., 2007, 72, 9379; H. Palencia, F. Garcia-Jimenez and J. M. Takacs, Tetrahedron Lett., 2004, 45, 3849; P. Langer, N. N. R. Saleh and I. Freifeld, Chem. Commun., 2002, 168; T. Muraki, H. Togo and M. Yokoyama, J. Chem. Soc., Perkin Trans. 1, 1999, 12, 1713.

38 S. Yurdakal, V. Loddo, G. Palmisano, V. Augugliaro, H. Berber and L. Palmisano, Ind. Eng. Chem. Res., 2010, 49, 6699.

39 M. A. Fox, R. B. Draper, M. Dulay and K. O'Shea, in Photochemical Conversion and Storage of Solar Energy, ed. E. Pellizzetti and M. Schiavello, Kluwer Academic Publishers, Netherlands, 1991, pp. 323-335.

40 X. Zhang, X. Ke, Z. Zheng, H. Liu and H. Zhu, Appl. Catal., B, 2014, 150, 330.

41 M. J. S. Dewar, J. Am. Chem. Soc., 1952, 74, 3357.

42 C. Jiménez-Sanchidrián and J. R. Ruiz, Tetrahedron, 2008, 64, 2011.

43 Q. Ma, W. Xing, J. Xu and X. Peng, Catal. Commun., 2014, 53, 5.

44 M. R. Klaas and S. Warwel, Org. Lett., 1999, 1, 1025. 